\title{
Subungual exostosis of the great toe: A case report
}

\author{
Kafle P', Rijal N², Pandey $\mathrm{AK}^{3}$
}

'Pradeep Kafle, Consultant Orthopaedic Surgeon, Department of Orthopaedic Surgery, Western Regional Hospital, Pokhara Academy of Health Sciences, Pokhara, Nepal; ${ }^{2}$ Nishchal Rijal, Consultant Orthopaedic Surgeon, Department of Orthopaedic Surgery, Dadeldhura Hospital, Dadeldhura, Nepal; ${ }^{3}$ Ashish Kumar Pandey, Assistant Professor, Department of Orthopaedics, B.P. Koirala Institute of Health Sciences, Dharan, Nepal.

\begin{abstract}
Subungual exostosis is typically a rare benign, acquired tumor of cartilaginous bone occurring on the medial surface of the distal hallux of toes or fingers. These are usually associated with secondary changes such as elevation of the nail plate, ulceration or subungual hyperkeratosis and hyperpigmentation. On histological examination, the lesion consists of mature bone at the base with proliferating fibrocartilaginous cap. A 14-year-old male presented with a solitary firm swelling gradually increasing in size for three months on the distal part of the right great toe. On physical examination, a firm, non-tender, non-mobile, whitish nodule was noted in the distal dorsomedial aspect of the right great toe distorting the adjacent nail. Radiographs demonstrated a dorsal bony outgrowth that was continuous with the distal phalanx. Excisional biopsy was done and on histopathological examination, a characteristic trabecular pattern of mature bone covered with a hyaline and fibrocartilaginous cap was seen. There was lack of true anaplasia, thereby confirming the diagnosis of subungual exostosis. There was no recurrence over six months. This topic is underrepresented in the orthopaedic literature, because many of the important clinical series have been published in journals from other branches of medicine i.e. mainly by dermatologists and pathologists. This reflects the fact that the condition is treated by many kinds of non-orthopaedic providers. We, as orthopaedic surgeons, must be careful while evaluating lesions of distal phalanges, always keeping in mind the possibility of subungual exostosis. Radiographs are helpful in diagnosis but confirmation can be done by histopathological examination. En bloc excision with minimal nail plate deformation can help prevent recurrence or deformity.
\end{abstract}

Key words: Exostosis; Fibrocartilaginous; Subungual.

DOI: https://doi.org/10.3126/jkmc.v8i4.32391

\section{INTRODUCTION}

ubungual exostosis (SE) is a relatively uncommon, Oosteocartilaginous tumor that affects the distal phalanx of the toes or fingers ${ }^{1}$.The condition, first described by Dupuytren in 1872 as a bony growth of the distal phalanx of the great toe, was initially known as 'Dupuytren's exostosis's ${ }^{3}$. Since the original description, there have been other cases described arising from the distal phalanx of other toes and the fingers ${ }^{4,5}$. The most common clinical presentation is that of several months

Address for correspondence

\section{Dr. Pradeep Kafle}

Consultant Orthopaedic Surgeon

Department of Orthopaedic Surgery

Western Regional Hospital, Pokhara Academy of Health Sciences

Pokhara, Nepal

E-mail: pradeepkafle@gmail.com

ORCID: https://orcid.org/0000-0001-7054-3359

ORCID: NishchalRijal:https://orcid.org/0000-0001-5948-6197

Ashish Kumar Pandey:https://orcid.org/0000-0001-6035-0705 of pain, erythema, and deformity of the nail bed. The lesion is nearly always solitary; the exception is when it occurs as a manifestation of the rare multiple exostosis syndrome ${ }^{6}$.

Usually, SE presents as a firm nodule at the free margin of the nail plate. These are typically associated with secondary changes such as elevation of the nail plate, ulceration or subungual hyperkeratosis and hyperpigmentation? ${ }^{7}$ On histological examination, the lesion consists of mature bone at the base with proliferating fibrocartilaginous $\mathrm{cap}^{6,8,9}$. In the subungual region, SE can easily be misdiagnosed as verruca vulgaris, glomus tumor, enchondroma,pyogenic granuloma, osteosarcoma or malignant melanoma ${ }^{10}$. Early recognition and accurate diagnosis of these lesions with their distinctive clinical, radiologic, and histopathologic features are critical in preventing overaggressive, sometimes mutilating therapy ${ }^{11}$. 
Currently there are no studies on prevalence and distribution of SE in Nepal. So this case report may provide an insight into the condition for the Orthopaedic surgeons in our country.

\section{CASE REPORT}

A14-year-old male presented on May 2019 with a solitary swelling on the distal part of right great toe. The boy first noticed the swelling three months prior to presentation and it was gradually increasing in size. There was no history of trauma to the affected digit and no history of fever. On physical examination, a firm, non-tender, non-mobile, whitish nodule was noted in the distal dorsomedial aspect of the right great toe distorting the adjacent nail (Figure 1). Radiographs demonstrated a dorsal bony outgrowth that was continuous with the distal phalanx. There was no evidence of periosteal reaction or bony destruction to suggest malignant or infective pathology (Figure 2).

Under spinal anesthesia, the distal part of nail was removed, en bloc excision of the tumour was done and the bony base was curetted (Figure 3). Primary closure of the wound was done. The surgical wound was cleaned with povidone-iodine and mupirocin ointment was applied. A firm bandage was wrapped around the great toe, and the limb was kept elevated. The dressing was changed on alternate days and sutures were removed at two weeks post-operatively.

On histopathological examination of the lesion, a characteristic trabecular pattern of mature bone covered with hyaline and fibrocartilaginous cap was seen. There was lack of true anaplasia, thereby confirming the diagnosis of subungual exostosis (Figure 4). Postoperative radiograph was taken which confirmed complete excision of the lesion (Figure 5).

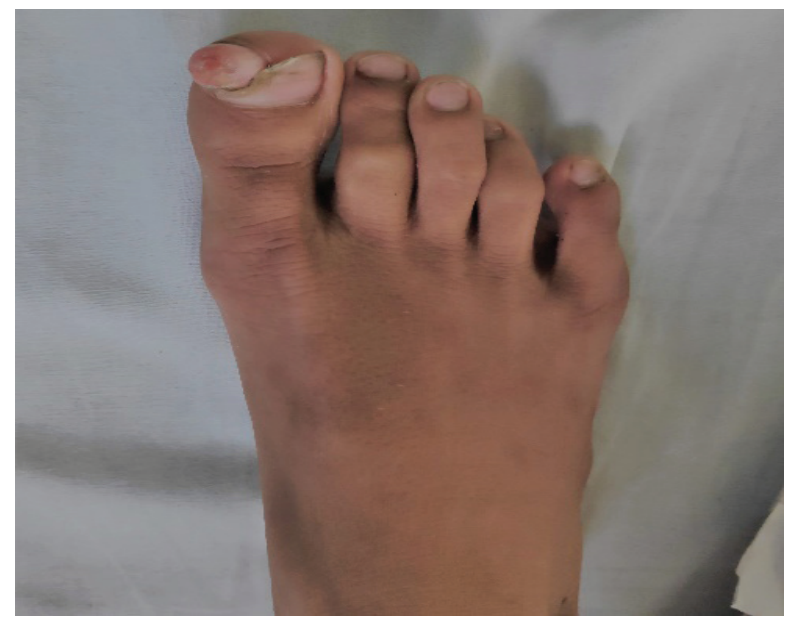

Figure 1: Subungual exostosis of right great toe

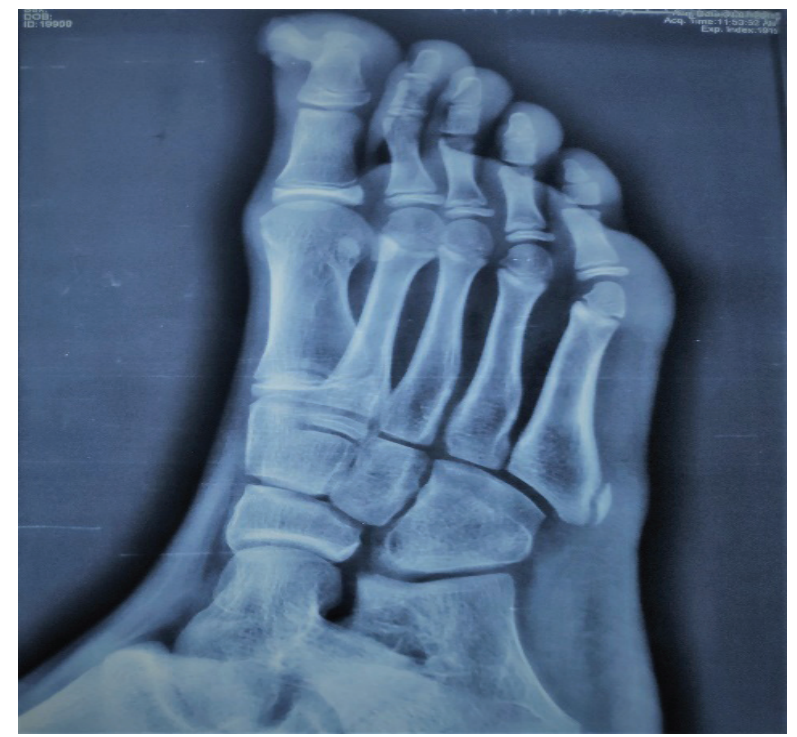

Figure 2: Pre-operative x-ray (oblique view)

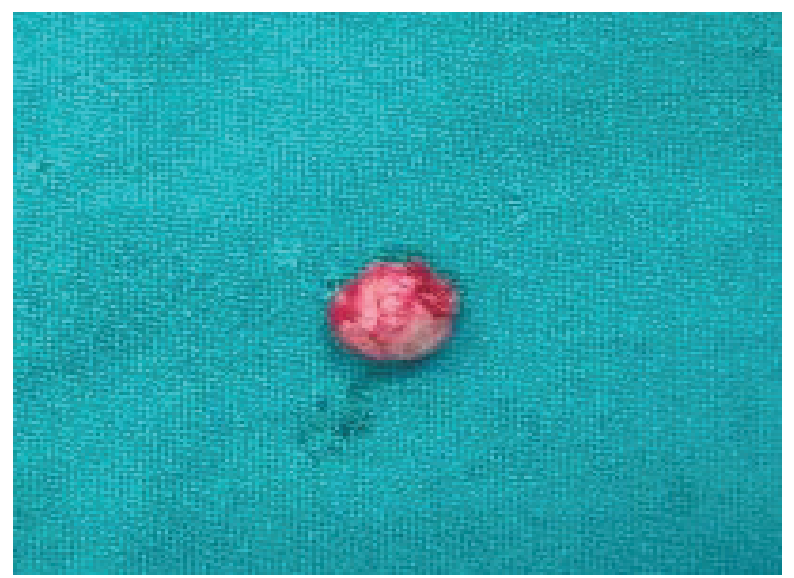

Figure 3: Excised mass
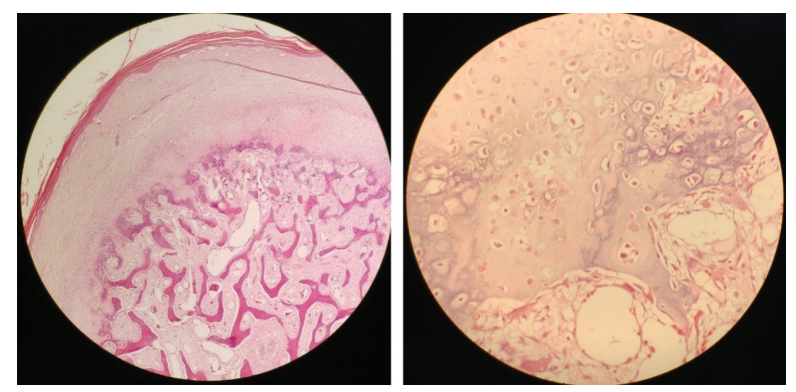

Figure 4: Histopathological image (low and high magnification) 


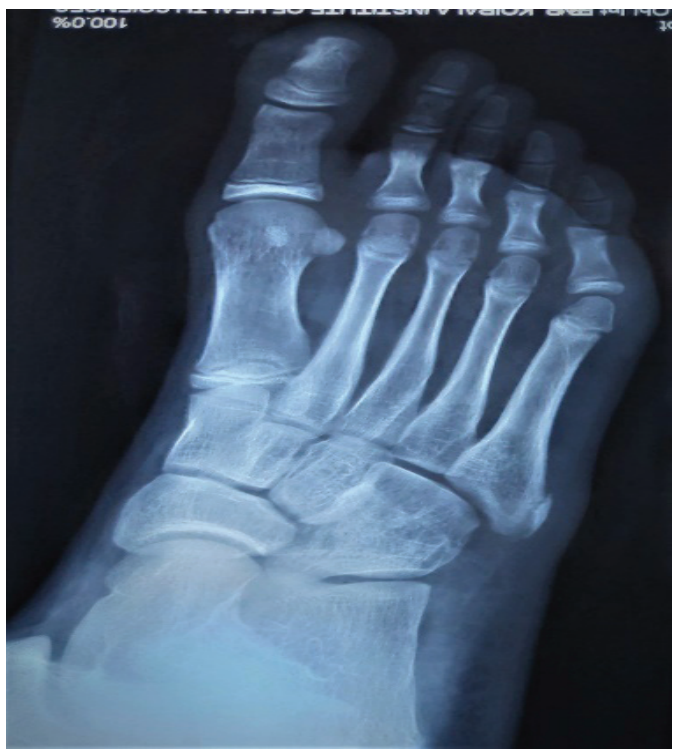

Figure 5: Post-operative radiograph (oblique view)

\section{DISCUSSION}

SE are uncommon benign tumors commonly located on the dorsum of the distal phalanx ${ }^{12}$. The exact pathogenesis is unclear, although trauma, infection, tumor, hereditary abnormality, or activation of a cartilaginous cyst all have been suggested as possible etiologies ${ }^{1}$.Although the tumors can occur at any age, $50 \%$ occur by 20 years and there is no marked difference between genders, although a slight predominance among females is noted ${ }^{6}$. Clinically the lesion appears as firm, shiny, smooth-surfaced white-yellow nodules ${ }^{13}$. The great toe is affected in $70 \%$ to $77 \%$ of the cases, followed by lesions on the other toes and in fingers ${ }^{9}$ ${ }^{14}$.Patients typically present with several months of pain, erythema, and deformity of the nail bed. However, in our case there was no complaint of pain; only of swelling and nail deformity.

Radiographically, the lesion appears as an osseocartilaginous mass on the dorsal surface of the distal phalan $x^{15}$. It is composed of mature trabeculated bone with attachment to the phalanx.The free end is flat, cupped and smooth, or irregular. There is no cortical disruption or any other associated abnormality of the distal phalanx ${ }^{16}$.

Histopathologically, the mature lesion consists of normal appearing bony structure within a fibrocartilaginous cap broadly contiguous with the underlying phalanx ${ }^{9}$. As maturation of the SE develops, the cartilaginous cap is replaced with trabecular bone and becomes thinner ${ }^{16}$. Multinucleated chondrocytes, pleomorphic nuclei and a prominent cellular structure are noted in the cartilaginous cap and this appearance may be confused with chondrosarcoma, if found in any other location. However, the trabecular bone of SE demonstrates regular maturation?.

There is debate whether subungual osteochondroma is the same clinical entity as $\mathrm{SE}^{1}$. Histologically, the cartilaginous cap of exostoses is made of fibrocartilage, whereas in osteochondromas, it is hyaline cartilage and is confluent with the underlying trabecular and cortical bone ${ }^{17,18}$. In exostoses, bone is formed directly from fibrous tissue, whereas in conventional osteochondromas, it is derived from enchondral ossification $^{8,17,19,20}$. The translocation $\mathrm{t}(\mathrm{X} ; 6)(\mathrm{q} 22 ; \mathrm{q} 13-14)$ has been reproducibly linked to $\mathrm{SE}^{20,21}$ implying it is a true neoplasm instead of being a reactive process in response to trauma.

SE is usually misdiagnosed as subungual verrucae, pyogenic granuloma, glomus tumor, carcinoma of the nail bed,subungual epidermal inclusion cyst, melanotic whitlow, onychocryptosis, enchondroma, and osteochondroma ${ }^{10}$

Our patient had a well-defined, smooth-surfaced pedunculated bony lesion in his right great toe, progressively increasing in size. He had no pain and presented to us with the complaint of abnormal swelling in his great toe. These clinical findings were consistent with subungual exostosis and our diagnosis was supported by radiographic as well as histopathological examination. En bloc resection of the lesion was done with curettage of the bony base. There was no recurrenceat six months follow up and normal growth of the excised nail occurred.

According to the systematic review by DaCambra et $\mathrm{al}^{1}$, the principle of treatment is to achieve complete excision of the lesion by curetting or burring down to normal trabecular bone while minimizing deformity to the nail plate. This approach is presumably associated with the lowest incidence of recurrence ${ }^{1}$. Recurrence was related to incomplete excision in most described cases; however, overly aggressive dissection was thought to lead to onychodystrophy and poor cosmesis ${ }^{22,23}$. The treatment in our case was in accordance with this study, as there was no recurrence or residual deformity after surgery.

The limitations of the study are: follow up was of short duration and our finding could not be correlated with the practice in our country due to lack of comparison studies. 


\section{CONCLUSION}

Hence, we report the successful treatment of an uncommon clinical condition. Because misdiagnosis and delayed diagnosis of this lesion are common, appropriate treatment often is not rendered. This topic is under represented in the orthopedic literature, because many of the important clinical series have been published in journals from other branches of medicine i.e. mainly by dermatologists and pathologists. This reflects the fact that the condition is treated by

\section{REFERENCES}

1. DaCambra MP, Gupta SK, Ferri-de-Barros F. Subungual exostosis of the toes: a systematic review. Clin Orthop Relat Res. 2014;472(4):1251-9.doi:10.1007/s11999013-3345-4

2. Dupuytren G. On the injuries and diseases of bones. Clark FL, editor. London: Sydenham Society; 1847.

3. Williams WR. Subungual exostosis. Bristol Med Chir J (1883). 1904;22(83):17.

4. Landon GC, Johnson K, Dahlin D. Subungual exostoses. J Bone Joint Surg Am. 1979;61(2):256-9.

5. Paget J. Lectures on surgical pathology: delivered at the Royal College of Surgeons of England: Lindsay \& Blakiston; 1865.

6. Davis DA, Cohen PR. Subungual exostosis: case report and review of the literature. Pediatr Dermatol. 1996;13(3):212-8.

7. Cohen HJ, Frank SB, Minkin W, Gibbs RC. Subungual exostoses. Arch Dermatol. 1973;107(3):431-2.

8. Evison G, Price C. Subungual exostosis. Br J Radiol. 1966;39(462):451-5.

9. Miller-Breslow A, Dorfman HD. Dupuytren's (subungual) exostosis. Am J Surg Pathol. 1988;12(5):368-78.

10. Apfelberg DB, Druker D, Maser MR, Lash H. Subungual osteochondroma: differential diagnosis and treatment. Arch Dermatol. 1979;115(4):472-3.

11. Singh R, Jain $M$, Goel R, Siwach R, Kalra R, Kaur K. Subungual exostosis of the great toe: a case report and tumor overview. Foot Ankle Spec. 2011;4(6):3768.doi: 10.1177/1938640011418495.

12. Eliezri YD, Taylor SC. Subungual Osteochondroma Diagnosis and Management. J Dermatol Surg Oncol. 1992;18(8):753-8. DOI: $10.1111 /$ j.1524-4725.1992. tb02010.x

13. Dawber RP, Baran R. Diseases of the nails and their management: Blackwell Scientific Publications; 1994.

14. Letts M, Davidson D, Nizalik E. Subungual exostosis: many kinds of non-orthopaedic providers. We, as orthopaedic surgeons, must be careful while evaluating lesions of distal phalanges, always keeping in mind the possibility of subungual exostosis. Radiographs are helpful in diagnosis but confirmation can be done by histopathological examination. En bloc excision with minimal nail plate deformation can help prevent recurrence or deformity. Also no articles about subungual exostosis have been published in Nepal and thus, this case helps in the further study of this condition.

diagnosis and treatment in children. J Trauma Acute Care Surg. 1998;44(2):346-9.doi:10.1097/00005373199802000-00020.

15. Palma Ld, Gigante A, Specchia N. Subungual exostosis of the foot. Foot Ankle Int. 1996;17(12):758-63. doi:10.1177/107110079601701208.

16. Ilyas W, Geskin L, Joseph AK, Seraly MP. Subungual exostosis of the third toe. J Am Acad Dermatol. 2001;45(6):S200-S1.doi:10.1067/mjd.2001.102666.

17. Ippolito E, Falez F, Tudisco C, Balus L, Fazio M, Morrone A. Subungual exostosis. Histological and clinical considerations on 30 cases. Ital J Orthop Traumatol. 1987;13(1):81-7.

18. Mertens F, Möller E, Mandahl N, Picci P, PerezAtayde AR, Samson I, et al. The $t(X ; 6)$ in subungual exostosis results in transcriptional deregulation of the gene for insulin receptor substrate 4 . Int J Cancer. 2011;128(2):487-91.doi:10.1002/ijc.25353.

19. Mavrogenis AF, Papagelopoulos PJ, Soucacos PN. Skeletal osteochondromas revisited. Orthopedics. 2008;31(10).

20. Dal Cin P, Pauwels $P$, Poldermans $L$, Sciot $R$, Van den Berghe $\mathrm{H}$. Clonal chromosome abnormalities in a so-called Dupuytren's subungual exostosis. Genes Chromosomes Cancer. 1999;24(2):162-4.

21. Storlazzi CT, Wozniak A, Panagopoulos I, Sciot R, Mandahl N, Mertens $F$, et al. Rearrangement of the COL12A1 and COL4A5 genes in subungual exostosis: molecular cytogenetic delineation of the tumorspecific translocationt (X; 6)(q13-14; q22). Int J Cancer. 2006;118(8):1972-6.doi:10.1002/ijc.21586.

22. Suga H, Mukouda M. Subungual exostosis: a review of 16 cases focusing on postoperative deformity of the nail. Ann Plast Surg. 2005;55(3):272-5. doi:10.1097/01. sap.0000174356.70048.b8.

23. De Berker D, Langtry J. Treatment of subungual exostoses by elective day case surgery. Br J Dermatol. 1999;140(5):915-8.[DOI] 